\title{
Black Girls And Referrals: Racial and Gender Disparities in Referral to Substance Use Disorder Screening in The Juvenile Justice System
}

Micah E Johnson ( $\square$ micahjohnson@usf.edu )

University of South Florida

Shawnta L Lloyd

University of Florida

Skye C Bristol

University of South Florida

Amy L Elliott

Sure Med Compliance

Linda B Cottler

University of Florida

\section{Research Article}

Keywords: Juvenile justice, gender health disparities, substance use disorder services, intersectionality

Posted Date: November 10th, 2021

DOI: https://doi.org/10.21203/rs.3.rs-1044517/v1

License: (9) This work is licensed under a Creative Commons Attribution 4.0 International License.

Read Full License 


\section{Abstract}

Background: Justice-involved children (JIC) have a high risk for illicit substance use (SU) and substance use disorders (SUD). Females are particularly vulnerable. It is critical that JIC who report current SU are referred for SUD screening to be provided with potentially life-saving treatment services. Florida law and Florida Department of Juvenile Justice (FLDJJ) policy mandate that JIC who report current SU be referred for SUD screening. Evidence suggests a racial referral gap among JIC who require SUD screening, and research on intersectionality suggests that these disparities may be exacerbated for minority females. Therefore, we hypothesize that Black and Latinx females will be less likely to be referred for SUD screening than White children despite reporting current substance use to FLDJJ.

Methods: Multivariate logistic regression was employed to analyze cross-sectional data from FLDJJ on 35,884 JIC who reported SU in the past six months. The main and interaction effects of race and gender on the likelihood of referral for SUD screening were tested. The control variables included substance type, age, household income, current SU problems, history of mental health problems, number of misdemeanors, and risk to recidivate.

Results: There were no significant differences in the likelihood of being referred for SUD screening between White females and White males. However, Black females (AOR=0.48), Latinx females (AOR= $0.77)$, and Black males $(A O R=0.76)$ were significantly less likely to be referred than White males. Black females were half as likely to be referred as White males and females.

Conclusion: This study finds evidence that Black females in the juvenile justice system are significantly underserved. The justice community must leverage these findings to implement protocols that ensure equal services for all children and eliminate gender and racial disparities in SUD screening.

\section{Background}

The failure to refer justice-involved children who report current substance use (SU) to adequate substance use treatment programs is a serious public health concern, as prolonged SU increases the likelihood of substance use disorder and other serious health conditions [1]. Undiagnosed substance use disorders (SUD) leads to untreated SUD among justice-involved children (JIC) that substantially contributes to the current substance abuse epidemic and substance trafficking crises in the United States (U.S.). Herein, the construct substance use (SU) refers to non-medical and/or illicit consumption of substances. Adolescent SU and untreated SUD are associated with violence [2], criminality [3, 4], risky sexual behavior [5], mental health problems [6, 7], justice-involvement and recidivism [8, 9], and other adverse outcomes [10].

In the U.S., it is estimated that out of 1.03 million adolescents between the ages of 12 and 17 that are diagnosed with SUD, nearly 969,000 or $75 \%$ did not receive substance use treatment [11]. This statistic only reports for adolescents who are actually properly screened and diagnosed and does not account for those misdiagnosed or never diagnosed. The co-morbidity of mental illness and SUD increases the likelihood of a misdiagnosis and ineffective use of resources. Evidence indicates that JIC are grossly 
under-screened for SUD; many JIC are never referred for SUD screening, even when current SU and associated problems are reported [12-15]. Referral for SUD screening is a critical point at which youth are screened, diagnosed and, if needed, provided with treatment and services. Referral for screening is particularly critical in the justice system because the juvenile justice system has arguably become the de facto drug treatment system in the United States for adolescent users. For many youths, involvement in the justice system may be the only opportunity to be properly screened, diagnosed, and treated.

In order for states to be eligible for federal juvenile justice grant funds, the U.S. Office of Juvenile Justice and Delinquency Prevention (OJJDP) requires that all states (1) track the processing of JIC through nine decision points and (2) address any racial disparities observed [16]. Some states, such as Florida, require that publicly funded justice institutions refer JIC who report current SU for SUD screening to determine which treatment and services are necessary [17]. FLDJJ policy dictates that all JIC who report current SU be automatically referred for SUD screening. Despite federal and state priorities to indiscriminately provide JIC with the necessary mental health services, very few studies have investigated racial disparities in referrals for SUD screening among JIC, and the review of the literature did not find any previous studies that examined the interaction effects of race and gender.

Racial disparities in services occur at several points in the juvenile justice process [18]. Black and Latinx $\mathrm{JIC}$ are especially underserved due to interpersonal and institutional discrimination and other social factors [19-21]. In a review of 26 studies, Spinney and colleagues (2016) found widespread racial disparities in the decision to provide JIC with mental health or substance abuse services. In a presentation at the College on Problems of Drug Dependence Annual Meeting, Elliott and colleagues [15] identified referrals for SUD screening as a key point where racial disparities occur. Among a sample of current substance users in the FLDJJ database-who are mandated to be referred for SUD screeningElliott and colleagues found that Black and Latinx children were less likely to be referred for SUD screening than White children [15]. These disparities may be exacerbated for minority girls. Research on the interaction effects of race and gender is needed.

Women and girls are often intentionally influenced to consume illicit substances by peers and sexual predators. Justice-involved females have higher risks of being exploited for sex, prostitution, and drug trafficking in comparison to justice-involved males and youth in the general population [22-24]. African American women in the criminal justice system endure an even greater risk of childhood and adult sexual trauma as well as substance abuse [25]. Addressing these public health issues is essential as women and girls often fill childbearing, caregiving, and leadership roles in their families, especially in Black and Latinx families. So, the biosocial consequences of untreated SUD among girls can proliferate to damage the entire family, community, and future generations.

Women and girls are more likely to face barriers to SUD screening and treatment services than men, including economic barriers, family responsibilities, and heightened stigma [26-28]. Additionally, sources of mandates to treatment differ for men and women, such that men may have more opportunities to receive treatment. Women are more likely to be referred to treatment by social workers, but men are more 
likely to be referred by family members, employers, and the criminal justice system [29]. These findings corroborate the need for an intersectional approach to investigating disparities in SUD screening among JIC.

Intersectionality is a scientific perspective that illuminates the unique experiences of individuals belonging to several disadvantaged groups (Collins \& Bilge, 2016). Conceptually, minority females represent the intersections of two marginalized statuses. In other words, the individual risks associated with minority status and the female gender have synergistic effects. Historically, intersectionality has illuminated the lived experiences of black women - a group at the intersection of race and gender that has fundamentally different experiences than those of the same race or gender separately. Applying an intersectional lens herein focuses the attention on justice-involved minority females and how disparities may impact them in referrals for SUD screening.

Alternatively to the intersections of marginalized statuses theory, disparities in referrals may be explained by sociodemographic, geographic, and other risk factors that attenuate the effect of race and gender on the likelihood of being referred for SUD screening [30-33]. While all Florida JIC who currently use substances are mandated to be flagged for referral, Florida law and FLDJJ also consider JIC's risk of recidivism. FLDJJ personnel may prioritize referrals for JIC: a) who use certain substances perceived as more dangerous, b) who are from low-income households, c) who are younger in age, d) with current SU problems, e) with a history of mental health problems, $f$ ) who are repeat offenders, and g) with a higher recidivism risk score. The Marchman Act specifically prioritizes JIC who are substance abuse offenders, substance abuse impaired at the time of arrest, second or subsequent offenders, or minors who are taken into custody [17]. These factors must also be considered to investigate disparities in referral for SUD screening appropriately.

\section{The Current Study}

Though Black and Latinx girls who use substances are often at higher risk for SUD and are subject to harsher consequences from lacking appropriate services than their white counterparts [34-36], previous data shows racial and gender disparities in referrals for SUD screening and services [37-40]. Yet still, the intersection of race and gender has not yet been examined. Using data from the Florida Department of Juvenile Justice (FLDJJ), this study investigates the effects of the intersection of race and gender on the likelihood of being referred for SUD screening. Applying an intersectionality-informed model, we hypothesized that justice-involved substance users who are Black females or Latinx females will be less likely to be referred for SUD screening than justice-involved substance users who are male or White. To our knowledge, this study is the first to examine the interaction effects of gender and race on referral for SUD screening among JIC in Florida. This research fills a striking void in the literature and advances efforts to eliminate health disparities among JIC.

\section{Methods}




\section{Population}

The study leveraged data from FLDJJ, which has collected comprehensive data on all youth entering the FLDJJ system since 2004. During intake, trained FLDJJ staff administered the Positive Achievement Change Tool (PACT) assessment through in-depth interviews and coded the data using the FLDJJ interface. The sample used in this study was drawn from the entire population of children in FLDJJ from 2005 to 2015 who reached the age of 18 before May $2015(N=80,441)$. Those who never reported current $\mathrm{SU}$ (neither alcohol nor drugs) were excluded from this sample. A sample of $35,884 \mathrm{JIC}$ met the selection criteria for the study, representing youth who reported using (non-medical or illicit) substances in the past six months. See CONSORT diagram in Figure 1. Among the study sample, $28.5 \%$ were White $(n=10,243)$, $56.9 \%$ of youth were Black $(n=20,434), 14.2 \%$ were Latinx $(n=5,087)$, and less than $1.0 \%$ were classified as other race $(n=120)$. Approximately $18 \%$ of the sample was female.

\section{Measures}

Referral for SUD Screening. The construct referral for SUD screening status was operationalized by a dichotomous variable reporting whether or not the youth was ever referred for SUD screening during the youth's involvement with FLDJJ (until March 31 st 2015 ). In accordance with the Marchman Act, these data are collected and maintained by FLDJJ officials. Response values were coded (0) "never referred for SUD screening" and (1) "yes, referred for SUD screening."

Race and Gender. Race is a construct that commonly includes ethnicity. Race was operationalized via a four-item nominal variable ( $0=$ White, $1=$ Black, $2=$ Latin $x, 3=$ other $)$. The nominal variable was converted into dummy variables using the STATA 13 "i." command to generate three dichotomous variables, Black ( $0=$ White, $1=$ Black), Latinx ( $0=$ White, $1=$ Latina), and other $(0=$ White, $1=$ other race). Gender is a social construct that includes the sex identifications male and female gender [41]. Many sexual minorities acknowledge gender as being less offensive and more inclusive and, therefore, it is used herein in place of sex. Gender was self-reported and categorized as a dichotomous measure $(0=$ male gender, $1=$ female gender). Race-by-gender was measured via an eight-item nominal variable ( $0=$ White male, $1=$ Black male, 2=Latinx male, $3=$ other male, $4=$ White female, $5=$ Black female, $6=$ Latinx female, and $7=$ other race female) that was converted into dummy variables

Covariates. The study controlled for substance type, household income, age, current SU problems, history of mental health problem, total misdemeanors, and recidivism risk level. The construct substance type referred to the types of substances being currently used. It was measured via a categorical variable recording the types of substances youth reported within the past six months. The response options were (0) alcohol only, (1) marijuana only, (2) alcohol and marijuana only, (3) other substance type, and (4) hard drugs. The "hard drugs" category included amphetamines, cocaine/crack, heroin and other opioids, inhalants, tranquilizers, and hallucinogens. There were limited cases among these options and therefore 
they were collapsed into the hard drug category. The "other substance type" category represented the youth who disclosed a substance type that was not listed on the FLDJJ intake assessment instrument.

The construct 'household income' was operationalized via a four-item ordinal variable reporting the combined annual income of the youth and their family. Response options were (0) under $\$ 15,000$, (1) from $\$ 15,000$ to $\$ 34,999$, (2) from $\$ 35,000$ to $\$ 49,999$, and (3) $\$ 50,000$ and above. The construct age was operationalized via an interval variable reporting the youth's age in 2015 -when all JIC aged-out of the system-that was derived from the youth's date of birth (Range: 18-26). Current SU problems were measured via a dichotomous variable that reported youths current problems related to drug and alcohol use experienced within the past six months. The response options were (0) none, meaning no current problems related to drug or alcohol use (including current and past users who have not experienced problems and (1) yes, current problems related to drug and/or alcohol use. The (1) yes response included those who reported that drug and/or alcohol disrupted school, caused family conflict, etc.

History of mental health problems was measured via a dichotomous variable at intake, reporting the youth's history of being diagnosed with mental health problems. Response items were (0) no history of mental health problems or (1) ever diagnosed with mental health problems. These data were either retrieved from a credentialed authority or self-reported data was verified by a credentialed authority. Adjudicated misdemeanors were measured via an ordinal variable reporting the amount of youth's misdemeanor adjudications in the FLDJJ system. The categories were (0) one or less, (1) two, (2) three or four, and (3) five or more.

The construct recidivism risk level was operationalized via FLDJJ's overall risk to re-offend measure. FLDJJ uses comprehensive data on criminal history and social factors to calculate a youth's overall risk to re-offend and corresponding recidivism risk level classification ( $0=$ low, $1=$ moderate, $2=$ moderate-high, $3=$ high). There were no issues with severe collinearity between the recidivism risk level variables and the other covariates in the study [for more information on the FLDJJ risk score, see 42].

\section{Analytical Procedures}

All analyses were completed in STATA 13 SE. Univariate analyses were conducted to describe the data. Bivariate analysis and multivariate logistic regression models were estimated to examine the relationship between race, gender, and control variables and the likelihood of referral to SUD screening. Chi-square tests were used to assess significant associations between all variables and referral status. An independent t-test was used to compare the mean age in individuals who were referred to SUD screening and those who were not referred to SUD screening. Multivariate models included the covariates described in the "Measures" subsection in Methods (age, household income, substance type used, SU problem, mental health problem, number of misdemeanors, and recidivism risk level). Multiplicative interaction terms were created using the STATA "\#" procedure and margins command. The interaction term was interpreted by estimating the predictive margins and plotting the predictive margins to graphically display 
the relationships. The study uses a complete case analysis; listwise deletion was used to omit cases that did not report current use.

\section{Results}

Table 1 displays the characteristics of JIC stratified by referral status. In the sample of JIC who reported current SU, 43\% $(15,422)$ were referred for SUD screening. Those who were referred for SUD screening were more likely to: be males (71.4\%), report current use of alcohol and marijuana only (27.1\%), have a household income between $\$ 15,000$ and $\$ 34,999$ (53.9\%), report current SU problems $(60.1 \%)$, report no history of mental health problems (67.9\%), have three or four misdemeanors (33.4\%), and have a moderately high recidivism risk level (33.4\%). Among those who were referred, $27 \%$ were White males, $44 \%$ were Black males, $13 \%$ were Latinx males, $7 \%$ were White females, $7 \%$ were Black females, and $2 \%$ were Latinx females. All variables were significant at the bivariate level, except household income and age.

Table 1: Characteristics of justice-involved children that reported current substance use who have and have not been referred to SUD screening for substance use 


\begin{tabular}{|c|c|c|c|c|}
\hline Characteristics & Overall & Not Referred & Referred & $p$ \\
\hline & $(n=35,884)$ & $(n=20,462))$ & $(n=15,422)$ & \\
\hline & $\mathrm{n}(\%)$ & $n(\%)$ & $n(\%)$ & \\
\hline Gender and Race & & & & $<0.0001$ \\
\hline White Male & $8,288(23.1)$ & $4,130(20.2)$ & $4,158(27.0)$ & \\
\hline Black Male & $16,625(46.3)$ & $9,773(47.8)$ & $6,852(44.4)$ & \\
\hline Latinx Male & $4,393(12.2)$ & $2,357(11.5)$ & $2,036(13.2)$ & \\
\hline White Female & $1,955(5.5)$ & $919(4.5)$ & $1,036.00(6.7)$ & \\
\hline Black Female & $3,809(10.6)$ & $2,801(13.7)$ & $1,008(6.5)$ & \\
\hline Latinx Female & $694(1.9)$ & $417(2.0)$ & $277(1.8)$ & \\
\hline Substance Type(s) Used & & & & $<0.0001$ \\
\hline Marijuana & $5,255(14.6)$ & $2,261(11.0)$ & $2,994(19.4)$ & \\
\hline Alcohol & $4,391(12.2)$ & $2,542(12.4)$ & $1,849(12.0)$ & \\
\hline Alcohol \& Marijuana & $6,187(17.2)$ & $2,000(9.8)$ & $4,187(27.1)$ & \\
\hline Hard Drugs & $3,716(10.4)$ & 718 (3.5) & $2,998(19.4)$ & \\
\hline Other Drug & $16,335(45.5)$ & $12,941(63.2)$ & $3,394(22.0)$ & \\
\hline Household Income & & & & 0.4500 \\
\hline Under $\$ 15,000$ & $10,560(29.4)$ & $6,067(29.7)$ & $4,493(29.1)$ & \\
\hline$\$ 15,000-\$ 34,999$ & 19,285 (53.7) & $10,977(53.6)$ & $8,308(53.9)$ & \\
\hline$\$ 35,000-\$ 49,999$ & $4,352(12.1)$ & $2,483(12.1)$ & $1,869(12.1)$ & \\
\hline$\$ 50,000$ and Over & $1,687(4.7)$ & $935(4.6)$ & $752(4.9)$ & \\
\hline Mean Age $( \pm s d)$ & $21.8(2.2)$ & $21.8(2.2)$ & $21.9(2.2)$ & 0.924 \\
\hline Substance Use Problems & & & & $<0.0001$ \\
\hline Yes & $14,003(39.0)$ & $4,741(23.2)$ & $9,262(60.1)$ & \\
\hline Mental Health Problem & & & & $<0.0001$ \\
\hline Yes & $9,157(25.5)$ & $4,205(20.6)$ & $4,952(32.1)$ & \\
\hline Misdemeanors & & & & $<0.0001$ \\
\hline 1 or Less & $12,821(35.7)$ & $9,074(44.3)$ & $3,747(24.3)$ & \\
\hline 2 & $7,467(20.8)$ & $4,176(20.4)$ & $3,291(21.3)$ & \\
\hline
\end{tabular}




\begin{tabular}{|ccccc|}
\hline 3-4 & $9,964(27.8)$ & $4,817(23.5)$ & $5,147(33.4)$ & \\
\hline 5 or More & $5,632(15.7)$ & $2,395(11.7)$ & $3,237(21.0)$ & \\
\hline Recidivism Risk Level & & & & \\
\hline Low & $10,449(29.1)$ & $7,526(36.8)$ & $2,923(19.0)$ & \\
\hline Moderate & $7,199(20.1)$ & $4,216(20.6)$ & $2,983(19.3)$ & \\
\hline Moderate-High & $10,827(30.2)$ & $5,683(27.8)$ & $5,144(33.4)$ & \\
\hline High & $7,409(20.7)$ & $3,037(14.8)$ & $4,372(28.3)$ \\
\hline Note: $p=p$-value of $\chi 2$ tests or $t$ test & & \\
\hline
\end{tabular}

Model 1 of Table 2 displays the results of multivariate logistic regression models examining the individual main effects of gender and race on the likelihood of being referred for SUD screening, while controlling for substance type, household income, age, current SU problems, history of mental health problems, number of misdemeanors, and recidivism risk level. Females (adjusted OR: 0.75, 95\% Cl: 0.700.80), Blacks (adjusted OR: 0.70; 95\% Cl: 0.66-0.75), and Latinx (adjusted OR: 0.89; 95\% Cl: 0.82-0.96) were significantly less likely to be referred for SUD screening than Whites and males, respectively. However, examining the main effects of race-by-gender together revealed more nuanced findings.

Table 2. Logistic Regression Estimating Odds Ratios of Referrals by Gender and Race 
Model 1

Main Effects

AOR

$\mathrm{Cl}$

$0.75^{\star \star \star}$

$[0.70,0.80]$

Model 2

Gender By Race

AOR $\quad \mathrm{Cl}$

\section{Gender and Race}

Gender (Ref=Male)

Female

Race (Ref=White)

Black

$0.70^{\star \star \star} \quad[0.66,0.75]$

Latinx

$0.89^{\star \star} \quad[0.82,0.96]$

\begin{tabular}{lll} 
Gender by Race (Ref= White Males) & & \\
\hline Black Male & $0.76^{\star \star \star}$ & {$[0.72,0.81]$} \\
\hline Latinx Male & 0.92 & {$[0.85,1.00]$} \\
\hline White Female & 0.99 & {$[0.88,1.11]$} \\
\hline Black Female & $0.48^{\star \star \star}$ & {$[0.44,0.53]$} \\
\hline Latinx Female & $0.77^{\star \star}$ & {$[0.64,0.93]$}
\end{tabular}

\section{Covariates}

Substance Type (Ref=Marijuana Only)

\begin{tabular}{|c|c|c|c|c|}
\hline Alcohol Only & $0.53^{\star \star \star}$ & {$[0.49,0.58]$} & $0.54^{\star \star \star}$ & {$[0.49,0.58]$} \\
\hline Marijuana \& Alcohol Only & $1.28^{\star \star \star}$ & {$[1.18,1.39]$} & $1.29^{\star \star \star}$ & {$[1.19,1.39]$} \\
\hline High Risk/Hard Drugs & $2.13^{\star \star \star}$ & {$[1.92,2.37]$} & $2.12^{\star \star \star}$ & {$[1.91,2.35]$} \\
\hline Other Drugs & $0.28^{\star \star \star}$ & {$[0.26,0.30]$} & $0.28^{\star \star \star}$ & {$[0.26,0.30]$} \\
\hline \multicolumn{5}{|l|}{ Income (Ref= Under $\$ 15 k)$} \\
\hline$\$ 15,000-\$ 34,999$ & $1.07^{\star}$ & {$[1.01,1.13]$} & $1.07^{\star}$ & {$[1.01,1.13]$} \\
\hline$\$ 35,000-\$ 49,999$ & 1.08 & {$[0.99,1.17]$} & 1.08 & {$[0.99,1.17]$} \\
\hline$\$ 50,000 \&$ Over & $1.17^{\star}$ & {$[1.03,1.33]$} & $1.18^{*}$ & {$[1.04,1.33]$} \\
\hline Age & $1.06^{* * *}$ & {$[1.05,1.08]$} & $1.06^{\star \star \star}$ & {$[1.05,1.08]$} \\
\hline
\end{tabular}


Yes

$1.95^{\star \star \star}$

$[1.85,2.07]$

$1.95^{\star \star *}$

$[1.84,2.06]$

Mental Health Problem (Ref. = None)

Yes, History of Problems

$1.31^{\star \star *} \quad[1.24,1.39] \quad 1.32^{\star \star \star} \quad[1.24,1.39]$

Misdemeanors (Ref $=1$ or Less)

\begin{tabular}{|c|c|c|c|c|}
\hline 2 & $1.44^{\star \star \star}$ & {$[1.35,1.55]$} & $1.44^{\star \star \star}$ & {$[1.35,1.54]$} \\
\hline $3-4$ & $1.73^{\star \star \star}$ & {$[1.62,1.85]$} & $1.74^{\star \star \star}$ & {$[1.63,1.85]$} \\
\hline 5 or More Misdemeanors & $1.95^{\star \star \star}$ & {$[1.80,2.11]$} & $1.95^{\star \star \star}$ & {$[1.80,2.11]$} \\
\hline \multicolumn{5}{|c|}{ Recidivism Risk Level (Ref=Low) } \\
\hline Moderate & $1.41^{\star \star *}$ & {$[1.31,1.51]$} & $1.41^{\star \star \star}$ & {$[1.31,1.51]$} \\
\hline Moderate-High & $1.63^{\star \star \star}$ & {$[1.53,1.75]$} & $1.63^{\star \star \star}$ & {$[1.53,1.75]$} \\
\hline High & $1.83^{\star \star \star}$ & {$[1.70,1.98]$} & $1.83^{\star \star \star}$ & {$[1.70,1.98]$} \\
\hline Observations & 35,884 & & 35,884 & \\
\hline Pseudo $R^{2}$ & 0.20 & & 0.20 & \\
\hline
\end{tabular}

Model 2 of Table 1 displays the association between the eight-item gender-by-race variable and referrals for SUD screening. There was no difference in the likelihood of being referred between White females and White males, and no difference in the likelihood of being referred between Latinx males and White males. However, compared to White males, Black males were $24 \%$ less likely to be referred (adjusted OR: 0.76; 95\% Cl: 0.72-0.81), Black females were 52\% less likely to be referred (adjusted OR: 0.48; 95\% Cl: 0.440.53), and Latinx females were $23 \%$ less likely to be referred (adjusted OR: 0.77; 95\% Cl: 0.64-0.93). In Figure 2, the predictive margins are plotted to graphically display the interaction effects of race and gender by substance type. Figure 2 illustrates that Blacks are less likely to be referred than other genderby-race groups across different types of SU profiles, but Black females suffer the greatest disparity.

\section{Discussion}

The aim of this study was to investigate the potential moderating effects of gender on the relationship between race and the likelihood of ever being referred for SUD screening among JIC who reported current SU. Despite FLDJJ policy mandating that JIC who report current SU be referred for SUD screening, JIC are under-referred across racial groups. However, there are also alarming racial and gender disparities. Among youth in the FLDJJ data, Black females who reported current SU were half as likely to be referred 
for SUD screening as White males and females who reported current SU while controlling for substance type(s), household income, age, current SU problems, history of mental health problem, total misdemeanors, and recidivism risk level.

Disparities in SUD screening and services among minority girls can have devastating consequences, especially during the current drug epidemic in the U.S. African American women are the foundation of the Black community and play a vital role in the social fabric of the U.S. as well as around the world. If the wellness of Black girls is diminished, it can devastate the Black community and proliferate to adversely affect populations across the U.S. The disparity in referral for SUD screening among Black girls found herein could be due to racial and gender biases among staff that favor males and Whites, such that Black girls are at the lowest tier of the preference hierarchy. These disparities could also be due to a presumption of resilience and/or low risk among Black girls, especially when compared to White boys and White girls. Although we controlled for the youth's actual risk level, staff presumptions of resilience or low risk among Black girls may contribute to these disparities.

Immediate steps can be taken to reduce disparities in referrals for SUD screening. The following key decision points are recommended for OJJDP reform policy: (1) the referral of all children for SUD screening when SU is reported; (2) the implementation of a disparity reduction strategy in the justice systems; and (3) the evaluation of disparity reduction progress via independent researchers. Researchers and the justice community must work together to identify the specific factors producing these disparities. Interpersonal biases may play a major role, and the justice community must prioritize training programs to reduce these biases and produce equality of services.

Systematic data collection and analysis by extramural researchers is key to monitoring and evaluating disparity reduction. FLDJJ has successfully provided independent researchers with access to these data to serve Florida children better. The justice community can benefit from this approach, and findings such as these that show disparities should not discourage data collection and sharing efforts. FLDJJ has made extraordinary progress toward reducing disparities and addressing the mental health needs of Florida children. These findings do not negate the accomplishments or strides made toward a more just and trauma-informed justice system in Florida and across the U.S. However, these findings show the elusiveness, complexity, and resilience of racial and gender disparities. Even in the context of FLDJJ and Florida statewide mandates to refer all current substance users for SUD screening, as well as state and federal efforts to reduce disparities, we still observe apparent racial and gender disparities. The justice community should embrace innovative, data-driven disparity reduction protocols and collaborations with independent researchers to assess progress.

\section{Limitations}

The results of this study are opportune, as it illustrated alarming disparities in SUD screening in the critical moment of a national and Florida substance abuse epidemic. It was the first study to leverage statewide data; Florida is the third-largest state population in America to investigate the interaction effects of race and gender on the likelihood of being referred for SUD screening. The sample was large 
and racially/ethnically diverse with a substantial female population. Despite its scientific merit, the study had some limitations. The study leverages cross-sectional data, which limits the ability to examine temporal sequencing. Longitudinal designs can address this shortcoming. The dataset had limited information on SU and SUD. Therefore, several cases were categorized as other drug types, and limited responses on the types of drugs used warranted collapsing several drugs into a single category, hard drugs. Future studies should include comprehensive and detailed information, including data on initiation, diagnoses, referral source, and frequency. Certain minority groups were underrepresented in the data, some of which may suffer harsher consequences from racial disparities in SUD services. For example, future research should investigate how potential racial disparities in referral for services impact Native American populations. Despite these limitations, this study found substantial evidence that JIC are underserved across racial groups, but Black girls are disproportionately impacted. The study also provided practical recommendations to reduce SU and health disparities among JIC.

\section{Conclusion}

Justice-involved children are a high-risk, understudied population that may face harsher consequences from substance use. Among this population, Black female JIC have a decreased likelihood for referral to SUD screening than their White male and female counterparts. This disparity increases the likelihood of SUD for Black female JIC who report current SU, as SUD may get misdiagnosed and result in adverse health outcomes. To effectively address this disparity, future studies should focus on understanding the factors that affect screening referrals through qualitative interviews to gather perspectives from key stakeholders.

\section{Abbreviations}

FLDJJ: Florida Department of Juvenile Justice

JIC: Justice-involved children

SU: Substance use disorder

SUD: Sustance use disorder

US: United States

\section{Declarations}

Ethics approval and consent to participate: All procedures were in accordance with the ethical standards of the institutional review boards, the 1964 Declaration of Helsinki, and its later amendments or comparable ethical standards. For this type of study, formal consent was not required. Approval was obtained from the Institutional Review Board at the University of South Florida. 
Consent for publication: All authors gave final approval to the publication of this manuscript.

Availability of data and materials: The research reported in this publication was approved by the Institutional Review Boards at the University of South Florida (STUDY001497) and the Florida Department of Juvenile Justice (FLDJJ). The data are not publicly available. Request for access must be made directly to FLDJJ. Several articles have been published using these data. However, the authors are not aware of any research which has used these data to investigate the specific relationships that are examined in the present study.

Competing interests: The authors declare no competing interests.

Funding: Research reported in this publication was supported by the UF Substance Abuse Training Center in Public Health and the National Institute on Drug Abuse under award numbers 1K01DA052679 (Dr. Micah Johnson, PI), R25DA050735 (Dr. Micah Johnson, PI), R25DA035163 (Dr. Carmen Masson, PI), and T32DA035167 (Dr. Linda Cottler PI). The content is solely the responsibility of the authors and does not necessarily represent the official views of the National Institutes of Health or the Florida Department of Juvenile Justice.

Authors' contributions MEJ: conceptualized and designed the study, interpreted and analyzed the data; drafted the manuscript; SLL: contributed to data analysis and provided contributions; SCB: provided contributions and revision of the manuscript; ALE: provided contributions and revision of the manuscript; LLC: conceptualized and designed the study, interpreted data, and revised manuscript

Acknowledgments: The data in this study were developed by and obtained from the Florida Department of Juvenile Justice (FLDJJ) in Tallahassee, Florida. Our team would like to acknowledge the dedicated professional at FLDJJ for managing the data and collaborating with investigators.

\section{References}

1. Schulte MT, Hser Y-I. Substance use and associated health conditions throughout the lifespan. Public Health Rev. 2014;35(2). doi: 10.1007/BF03391702.

2. Chassin L, Dmitrieva J, Modecki K, Steinberg L, Cauffman E, Piquero AR, et al. Does adolescent alcohol and marijuana use predict suppressed growth in psychosocial maturity among male juvenile offenders? Psychol Addict Behav. 2010;24(1):48-60. doi: 10.1037/a0017692.

3. Young DW, Dembo R, Henderson CE. A national survey of substance abuse treatment for juvenile offenders. J Subst Abuse Treat. 2007;32(3):255-66. doi: 10.1016/j.jsat.2006.12.018.

4. Mason WA, Windle M. Reciprocal relations between adolescent substance use and delinquency: $A$ longitudinal latent variable analysis. Journal of Abnormal Psychology. 2002;111(1):63-76. doi:

10.1037//0021-843X.111.1.63. 
5. Teplin LA, Elkington KS, McClelland GM, Abram KM, Mericle AA, Washburn JJ. Major mental disorders, substance use disorders, comorbidity, and hiv-aids risk behaviors in juvenile detainees. Psychiatr Serv. 2005;56(7):823-8. doi: DOI 10.1176/appi.ps.56.7.823.

6. Grella CE, Hser YI, Joshi V, Rounds-Bryant J. Drug treatment outcomes for adolescents with comorbid mental and substance use disorders. Journal of Nervous and Mental Disease. 2001;189(6):384-92. doi: Doi 10.1097/00005053-200106000-00006.

7. Teplin LA, Welty LJ, Abram KM, Dulcan MK, Washburn JJ, McCoy K, et al. Psychiatric disorders of youth in detention. Office of Juvenile Justice and Delinquency Prevention,U.S. Department of Justice (www.ojp.usdoj.gov ); 2015.

8. McReynolds LS, Schwalbe CS, Wasserman GA. The contribution of psychiatric disorder to juvenile recidivism. Criminal Justice and Behavior. 2010;37(2):204-16. doi: 10.1177/0093854809354961.

9. Schubert CA, Mulvey EP, Glasheen C. Influence of mental health and substance use problems and criminogenic risk on outcomes in serious juvenile offenders. J Am Acad Child Adolesc Psychiatry. 2011;50(9):925-37. doi: 10.1016/j.jaac.2011.06.006.

10. King KM, Meehan BT, Trim RS, Chassin L. Marker or mediator? The effects of adolescent substance use on young adult educational attainment. Addiction. 2006;101(12):1730-40. doi: 10.1111/j.13600443.2006.01507.x.

11. Marotta PL, Tolou-Shams M, Cunningham-Williams RM, Washington DM, Voisin D. Racial and ethnic disparities, referral source and attrition from outpatient substance use disorder treatment among adolescents in the united states. Youth \& Society. 2020:0044118X20960635. doi:

$10.1177 / 0044118 \times 20960635$.

12. Kates E, Gerber EB, Casey S. Prior service utilization in detained youth with mental health needs. Adm Policy Ment Health. 2014;41(1):86-92. doi: 10.1007/s10488-012-0438-4.

13. Pullmann MD, Heflinger CA. Community determinants of substance abuse treatment referrals from juvenile courts: Do rural youths have equal access? Journal of Child \& Adolescent Substance Abuse. 2009;18(4):359-78. doi: 10.1080/10678280903185518.

14. Shelton D. Patterns of treatment services and costs for young offenders with mental disorders. J Child Adolesc Psychiatr Nurs. 2005;18(3):103-12. doi: 10.1111/jcap.2005.18.issue-3.

15. Elliott AL, Cottler LB, Johnson ME. Racial/ethnic disparities in referral for substance use disorder screening among florida justice-involved children. The CPDD 80th Annual Scientific Meeting; San Diego, California: College on Problems of Drug Dependence; 2018.

16. OJJDP. Disproportionate minority contact technical assistance manual. 2009. doi, 
17. Hal s. Marchman alcohol and other drug services act of 1993, Stat. 397, F.S. (2003).

18. Cohen M, W illiam Feyerherm, Spinney E, Stephenson R, Yeide M. Expanding use of dmc data analysis of patterns to identify best practices. Presentation at American Society of Criminology Annual Meeting; November 16-19; Washington, DC2011.

19. Garland AF, Lau AS, Yeh M, McCabe KM, Hough RL, Landsverk JA. Racial and ethnic differences in utilization of mental health services among high-risk youths. Am J Psychiatry. 2005;162(7):1336-43. doi: 10.1176/appi.ajp.162.7.1336.

20. Dalton RF, Evans LJ, Cruise KR, Feinstein RA, Kendrick RF. Race differences in mental health service access in a secure male juvenile justice facility. J Offender Rehabil. 2009;48(3):194-209. doi: $10.1080 / 10509670902766570$.

21. Rawal P, Romansky J, Jenuwine M, Lyons JS. Racial differences in the mental health needs and service utilization of youth in the juvenile justice system. J Behav Health Serv Res. 2004;31(3):242-54. doi: 10.1097/00075484-200407000-00002.

22. Lynch SM, Heath NM, Mathews KC, Cepeda GJ. Seeking safety: An intervention for trauma-exposed incarcerated women? J Trauma Dissociation. 2012;13(1):88-101. doi: 10.1080/15299732.2011.608780.

23. Najavits LM, Weiss RD, Shaw SR. A clinical profile of women with posttraumatic stress disorder and substance dependence. Psychol Addict Behav. 1999;13(2):98-104. doi: Doi 10.1037/0893-164x.13.2.98.

24. Klein H, Chao BS. Sexual abuse during childhood and adolescence as predictors of hiv-related sexual risk during adulthood among female sexual partners of injection drug users. Voilence Against Women. 1995;1(1):55-76. doi: 10.1177/1077801295001001004.

25. Richie BE, Johnsen $C$. Abuse histories among newly incarcerated women in a new york city jail. Journal of the American Medical Women's Association (1972). 1996;51(3):111-4, 7. doi,

26. Brady KT, Randall CL. Gender differences in substance use disorders. Psychiatr Clin North Am. 1999;22(2):241-52. doi,

27. Thom B. Sex differences in help-seeking for alcohol problems-2. Entry into treatment. Br J Addict. 1987;82(9):989-97. doi,

28. Brady TM, Ashley OS. Women in substance abuse treatment: Results from the alcohol and drug services study (adss). Rockville, MD: Substance Abuse and Mental Health Services Administration, Office of Applied Studies; 2005. Contract No.: DHHS Pub. No. SMA 04-3968,.

29. Grella CE, Joshi V. Gender differences in drug treatment careers among clients in the national drug abuse treatment outcome study. American Journal of Drug and Alcohol Abuse. 1999;25(3):385-406. doi: Doi 10.1081/Ada-100101868. 
30. Newacheck PW, Hung YY, Park MJ, Brindis CD, Irwin CE. Disparities in adolescent health and health care: Does socioeconomic status matter? Health Serv Res. 2003;38(5):1235-52. doi: 10.1111/14756773.00174 .

31. Howard MO, Balster RL, Cottler LB, Wu LT, Vaughn MG. Inhalant use among incarcerated adolescents in the united states: Prevalence, characteristics, and correlates of use. Drug and alcohol dependence. 2008;93(3):197-209. doi: 10.1016/j.drugalcdep.2007.08.023.

32. Cavazos-Rehg PA, Krauss MJ, Spitznagel EL, Schootman M, Cottler LB, Bierut LJ. Substance use and the risk for sexual intercourse with and without a history of teenage pregnancy among adolescent females. J Stud Alcohol Drugs. 2011;72(2):194-8. doi: 10.15288/jsad.2011.72.194.

33. Spinney E, Yeide M, Feyerherm W, Cohen M, Stephenson R, Thomas C. Racial disparities in referrals to mental health and substance abuse services from the juvenile justice system: A review of the literature. $J$ Crime Justice. 2016;39(1):153-73. doi: 10.1080/0735648x.2015.1133492.

34. Abram KM, Choe JY, Washburn JJ, Romero EG, Teplin LA. Functional impairment in youth three years after detention. The Journal of adolescent health: Official publication of the Society for Adolescent Medicine. 2009;44(6):528-35. doi: 10.1016/j.jadohealth.2008.10.005.

35. Feldstein Ewing SW, Venner KL, Mead HK, Bryan AD. Exploring racial/ethnic differences in substance use: A preliminary theory-based investigation with juvenile justice-involved youth. BMC Pediatr. 2011;11:71. doi: 10.1186/1471-2431-11-71.

36. McHugh RK, Votaw VR, Sugarman DE, Greenfield SF. Sex and gender differences in substance use disorders. Clin Psychol Rev. 2018;66:12-23. doi: 10.1016/j.cpr.2017.10.012.

37. Cummings JR, Wen H, Druss BG. Racial/ethnic differences in treatment for substance use disorders among u.S. Adolescents. J Am Acad Child Adolesc Psychiatry. 2011;50(12):1265-74. doi: 10.1016/j.jaac.2011.09.006.

38. Alegria M, Carson NJ, Goncalves M, Keefe K. Disparities in treatment for substance use disorders and co-occurring disorders for ethnic/racial minority youth. J Am Acad Child Adolesc Psychiatry. 2011;50(1):22-31. doi: 10.1016/j.jaac.2010.10.005.

39. Marie BS, Sahker E, Arndt S. Referrals and treatment completion for prescription opioid admissions: Five years of national data. J Subst Abuse Treat. 2015;59:109-14. doi: 10.1016/j.jsat.2015.07.010.

40. Pagano ME, Raj NM, Rhodes $C$, Krentzman AR, Little M. Identifying strengths in youths at substance use treatment admission. The American Journal of Drug and Alcohol Abuse. 2019;45(4):410-20. doi: 10.1080/00952990.2019.1603302.

41. West C, Zimmerman DH. Doing gender. Gender and Society. 1987;1(2):125-51. doi: 10.1177_0891243287001002002. 
42. Early KP, Hand GA, Blankenship JL. Validity and reliability of the florida pact risk and needs assessment instrument: A three-phase evaluation. 2012:1-123. doi, http://www.djj.state.fl.us/docs/probation-policy-memos/jrc-comprehensive-pact-validity-and-reliabilitystudy-report-2012.pdf?Status=Master\&sfvrsn=2

\section{Figures}

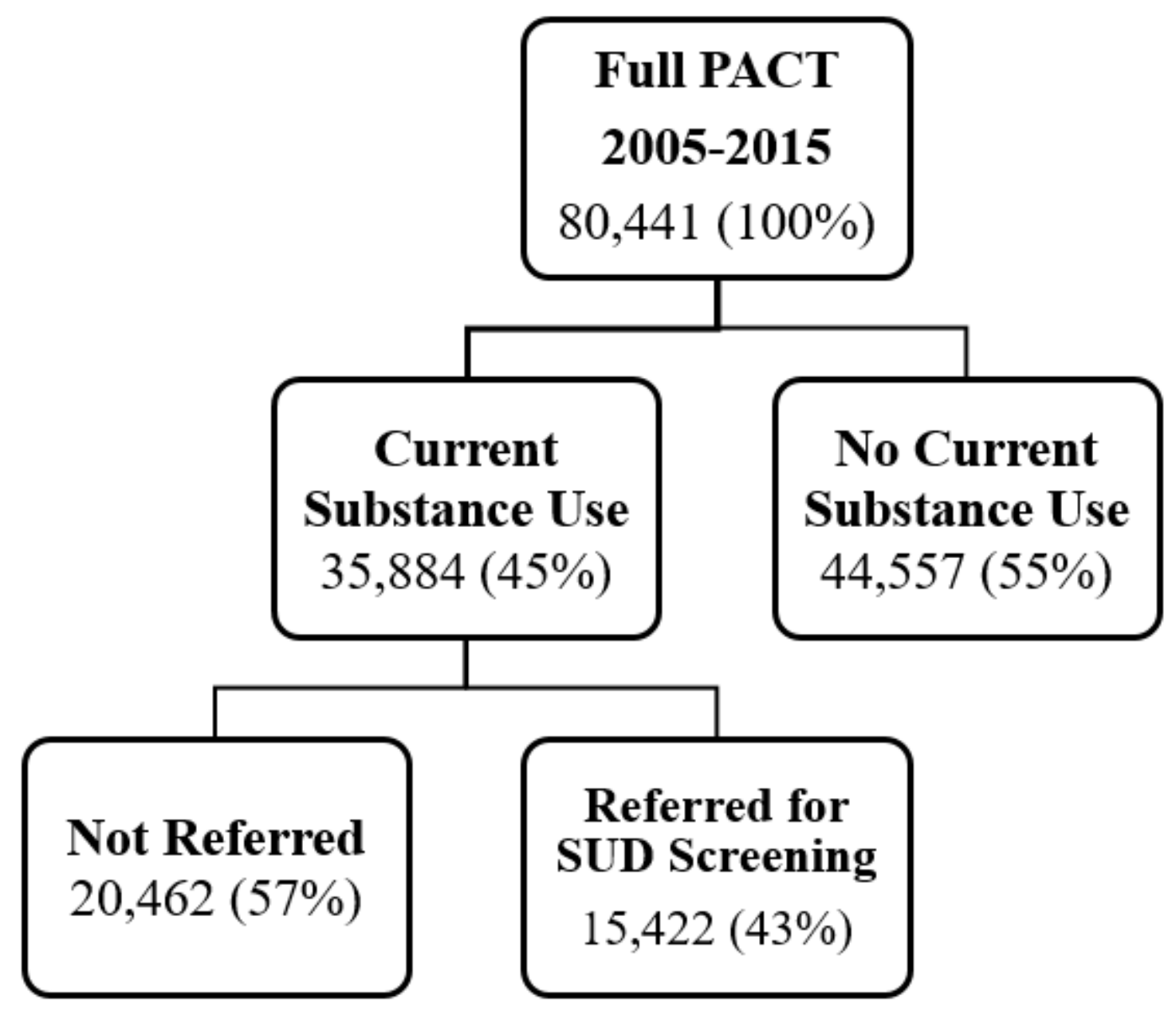

Figure 1

Flow Diagram of FLDJJ Data on Referral for SUD Screening Status. Not currently using were excluded because non-current users do not fit the criteria for referral for SUD. Referral for SUD is conditional on current SU. 


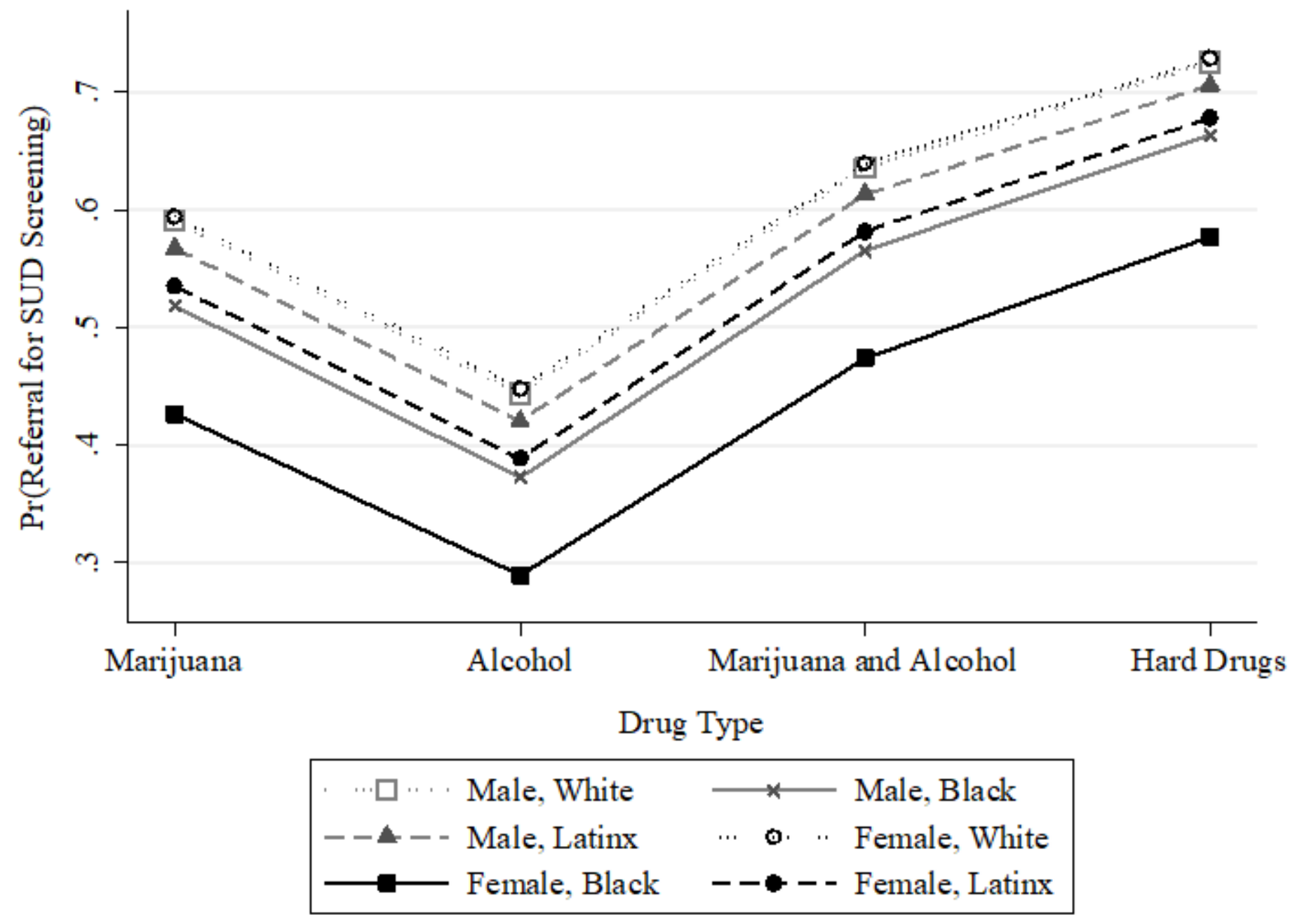

Figure 2

Predicted margins (Pr) of referrals for SUD screening by gender, race, and drug type. $\mathrm{N}=35,884$ (drug type category "other drugs" not displayed). 